\title{
Evidence for a Phytoreovirus Associated with Tobacco Exhibiting Leaf Curl Symptoms in South Africa
}

\author{
Marie Emma Christine Rey, Elvera D’Andrea, Jennifer Calvert-Evers, Maria Paximadis, and Guido Boccardo
}

First, second, third, and fourth authors: Department of Microbiology, University of the Witwatersrand, P.O. Wits 2050, Johannesburg, South

Africa; fifth author: CNR, Istituto di Fitovirologia Applicata, Str. delle Cacce 73, 10135 Torino, Italy.

Accepted for publication 13 January 1999.

\begin{abstract}
Rey, M. E. C., D’Andrea, E., Calvert-Evers, J., Paximadis, M., and Boccardo, G. 1999. Evidence for a phytoreovirus associated with tobacco exhibiting leaf curl symptoms in South Africa. Phytopathology 89:303307.

Three forms of tobacco leaf curl (termed classes I, II, and III, based on symptomatology) recently have been described in southern Africa. $\mathrm{Nu}$ merous attempts to isolate virus particles responsible for a nongeminivirusinduced leaf curl disease (class I) of tobacco in South Africa have been unsuccessful. Recently, 12 dsRNA segments were isolated from tobacco exhibiting class I leaf curl symptoms, suggesting a possible reovirus genome. The objective of our study was to confirm whether the dsRNA segments are associated with a reovirus. Isolation of icosahedral particles with an outer core 60 to $65 \mathrm{~nm}$ in diameter and an inner core 40 to $45 \mathrm{~nm}$ in

isolated from purified virions, and the total molecular masses of the dsRNAs ranged from 17.86 to $18.40 \times 10^{6} \mathrm{Da}$ in polyacrylamide and agarose gels, respectively. Using hybridization analysis, dsRNAs were identified as nonhomologous distinct segments. Comparisons with other known reoviruses revealed a unique banding pattern that was most similar to the wound tumor virus (WTV), the type species of the genus Phytoreovirus. Hybridizations of WTV cloned DNA probes (segments S4 and S6 to S9) and dsRNAs from infected tobacco indicated no significant sequence similarity, whereas indirect enzyme-linked immunosorbent assay with a polyclonal antiserum to WTV showed strong positive cross-reactivity to tobacco virions. Our results indicate a virus with features consistent with those of phytoreoviruses. This is the first report of a plant reovirus in tobacco, the first record in Africa, and the second example of a fieldisolated dicot phytoreovirus.
\end{abstract} diameter was achieved. Twelve distinct nonpolyadenylated dsRNAs were
Tobacco leaf curl disease was once one of the most destructive diseases in East Africa, Zimbabwe, and South Africa (16) and is currently widespread in India (32). At present in southern Africa, epidemics are sporadic and not as devastating as in the past (31). Specific symptoms in plants exhibiting leaf curl vary widely with respect to type and severity (23). Variable leaf curl symptoms displayed by tobacco worldwide may be due to a complex of viruses or virus strains, but this theory has not been proven. The most characteristic symptoms of tobacco leaf curl are leafy outgrowths (enations) from veins on the lower surface of curled and twisted leaves. Leaves also contain thickened veins and are much reduced in size compared with uninfected leaves (16). In 1978, Osaki and Inouye (23) extracted geminate viral particles associated with tobacco leaf curl in Japan. The tobacco leaf curl virus Osaki and Inouye (24) characterized belongs to the family Geminiviridae and occurs mainly in tropical and subtropical regions, but it also has been reported in temperate regions.

Numerous attempts to isolate geminivirus particles from tobacco plants with leaf curl symptoms in South Africa have been unsuccessful, but recently, a geminivirus was confirmed in leaf curlinfected tobacco from Zimbabwe $(6,7,26,31)$. Tobacco plants from South Africa and Zimbabwe exhibiting variable leaf curl symptoms have been grouped in three classes based on symptomatology and common virus particles or viral nucleic acids $(25,26)$. Class I tobacco leaf curl-infected plants have characteristic leafy enations on the underside of leaves. Vein thickenings are clearly visible, and leaves are curled and twisted (Fig. 1). Tumors also have been observed on roots of affected tobacco plants. Twelve dsRNA seg-

Corresponding author: M. E. C. Rey; E-mail: chrissie@gecko.biol.wits.ac.za

Publication no. P-1999-0212-02R

(C) 1999 The American Phytopathological Society ments have been found consistently in class I-infected tobacco plants and are absent from class II- and III-infected tobacco plants. The double-stranded nature of the RNAs was confirmed by ribonuclease digestion under both high- and low-salt conditions (25). Mechanical and seed transmissions of dsRNAs from class I-infected tobacco plants were unsuccessful (25). Class II tobacco symptoms are visible in tobacco plants germinated from seed, and a possible inherited genetic disorder is suspected (26). Class III tobacco symptoms are associated with geminivirus infection (26).

Plant reoviruses (family Reoviridae) can be placed in one of three genera, Phytoreovirus, Fijivirus, or Oryzavirus, and include a garlic dwarf reovirus (GDV) (15) that has an uncertain taxonomic position (11). Reoviruses have been isolated from South and Far East Asia, Europe, Australia, and North and South America. Genomes consist of 10 to 12 dsRNA segments, (S1 to S12, in order of slowest to fastest mobility in polyacrylamide gel electrophoresis [PAGE]) and are packaged in inner cores $\approx 40 \mathrm{~nm}$ in diameter

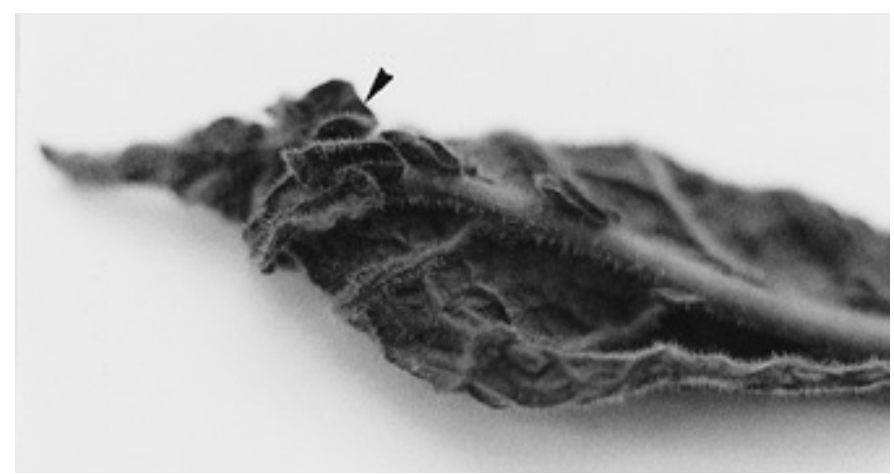

Fig. 1. Tobacco leaf exhibiting class I leaf curl symptoms: leafy enations (arrow) and thickened veins. 
and outer protein shells 60 to $80 \mathrm{~nm}$ in diameter $(5,8,11,13)$. Plant reoviruses are not efficiently sap (mechanically) transmissible but are transmitted by leafhoppers. Infectivity can be determined only by injecting preparations into virus-free vectors tested for the ability to transmit the virus to susceptible plants (11). Plant reovirus-like symptoms include enations, vein swellings, and dwarfing (11). Wound tumor phytoreovirus (WTV) is the only plant reovirus known to infect dicotyledonous plants $(21,22)$. Although tobacco has not been recorded as a natural host for plant reoviruses, the dsRNA evidence previously reported suggests the presence of a plant-infecting reovirus in class I-infected tobacco plants $(25,26)$. The objective of our work was to determine whether the dsRNA segments isolated from class I leaf curl-infected tobacco plants represents the genome of a reovirus.

\section{MATERIALS AND METHODS}

Virus extractions. Reovirus extractions, using a modification of the method described by Kimura (12), were performed on healthy, symptomless tobacco (control) and class I-infected tobacco plant materials (Nicotiana tabacum cvs. TL33 and TL38). Extractions were performed several times with $50 \mathrm{~g}$ of frozen $\left(-80^{\circ} \mathrm{C}\right)$ leaf material per extraction. A single extraction with $150 \mathrm{~g}$ of fresh leaf material also was performed. Field-grown tobacco plants were collected from two cultivation areas in the western and eastern regions of South Africa over four growing seasons and maintained in the greenhouse. After extraction in buffer $(0.05 \mathrm{M}$ sodium phosphate buffer, $\mathrm{pH} 7.8$, containing $5 \mathrm{mM} \mathrm{Na}_{2}$ EDTA and $10 \mathrm{mM}$ diethyldithiocarbamate) and clarification with $20 \%$ carbon tetrachloride, the supernatant was centrifuged in a JA-14 centrifuge (Beckman Instruments, Fullerton, CA) at $6,000 \mathrm{rpm}$ for $10 \mathrm{~min}$ at $4^{\circ} \mathrm{C}$. The supernatant was distributed in five centrifuge tubes, placed in a Beckman type 42.1 rotor, and centrifuged through $20 \%$ sucrose cushions at $30,000 \mathrm{rpm}$ for $45 \mathrm{~min}$ at $4^{\circ} \mathrm{C}$ in a Beckman L8-55 ultracentrifuge. Pellet was resuspended in $0.05 \mathrm{M}$ sodium phosphate buffer ( $\mathrm{pH}$ 7.8) (partially purified virus preparation), and the sample was purified further by centrifugation through a sucrose density gradient (10 to 50\%) in $0.05 \mathrm{M}$ sodium phosphate buffer ( $\mathrm{pH} 7.8)$ for $2 \mathrm{~h}$ at 27,000 rpm and $4^{\circ} \mathrm{C}$ (Beckman L8-55 ultracentrifuge and SW28 rotor). Virions recovered from the viral band were resuspended in $0.05 \mathrm{M}$ sodium phosphate buffer $(\mathrm{pH} 7.8)$ containing a few crystals of chlorobutanol for preservation and stained with either $2 \%$ sodium

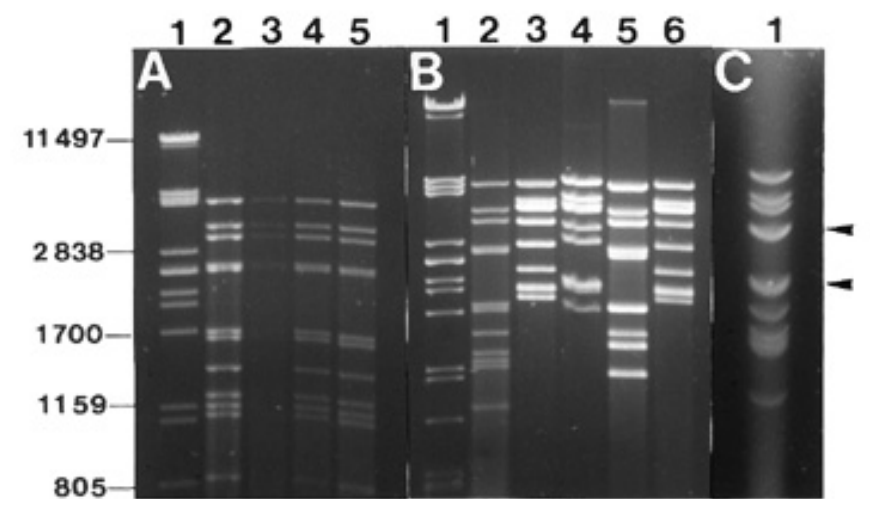

Fig. 2A, Agarose gel (1\%) of dsRNAs isolated from class I-infected tobacco. Lane 1, PstI-digested lambda dsDNA molecular markers, sizes (base pairs) of markers are indicated to the left; lanes 2 through 5, dsRNAs isolated from leaf curl-infected tobacco. B, Agarose gel (1\%) of dsRNAs isolated from class I-infected tobacco (lane 2) for comparison with dsRNAs from other plantinfecting reoviruses: lane 3, maize rough dwarf fijivirus; lane 4, garlic dwarf reovirus; lane 5, rice dwarf reovirus; and lane 6 , rice black-streaked dwarf fijivirus. Lane 1, PstI-digested lambda dsDNA molecular weight markers. Twelve dsRNA segments (sizes are provided in Table 1) in infected tobacco (lane 2) show a different pattern compared with other reoviruses. C, Agarose gel (1\%) of dsRNAs extracted from purified virus particles isolated from infected tobacco; there are 10 segments, but bands 4 and 5 and 6 and 7 (arrows) are doublets. phosphotungstate or $2 \%$ uranyl acetate for $15 \mathrm{~min}$ and viewed under a JEM S-100 electron microscope (Jeol, Tokyo) (9). Virus yields were estimated roughly by spectrophotometry $\left(A_{260 \mathrm{~nm}}, 1-\mathrm{cm}\right.$ light path).

Extraction of dsRNA from virions. One volume of sucrose density gradient-purified virions was incubated in one volume of disassociation buffer ( $2 \%$ sodium dodecyl sulfate [SDS], $2 \mathrm{mM}$ EDTA, and proteinase $\mathrm{K}$ at $100 \mu \mathrm{g} / \mathrm{ml}$ ) at $50^{\circ} \mathrm{C}$ for $2 \mathrm{~h}$, and the mixture was extracted as described by Paximadis et al. (25).

Extraction of dsRNA from class I-infected tobacco plants. The method used to extract dsRNA from class I-infected tobacco plants was essentially the method described by Morris and Dodds (20). dsRNA also was extracted from healthy tobacco plants as a control. Detection of possible poly(A) tracts at the $3^{\prime}$ ends of dsRNAs was performed using the oligo (dT) trapping method (Amersham International, Little Chalfont, England). As positive controls, mRNAs (cDNA cloning kit, Boehringer $\mathrm{GmbH}$, Mannheim, Germany) were used at 10-, 100-, and 1,000-ng concentrations.

Agarose gel electrophoresis. dsRNAs from virions and infected tobacco leaves were separated and analyzed directly on $1 \%$ agarose gels stained with ethidium bromide $(0.5 \mu \mathrm{g} / \mathrm{ml}$ final concentration) (30). Segments were separated at 60 to $100 \mathrm{~V}$ with a E321 power supply (Consort nv, Belgium) at room temperature for 1 to $4 \mathrm{~h}$. Purified dsRNAs from tobacco were coelectrophoresed on agarose gels with dsRNA from other known plant-infecting reoviruses as comparisons. Known viruses included maize rough dwarf fijivirus (MRDV); GDV (15); rice dwarf phytoreovirus (RDV); and rice black-streaked dwarf fijivirus (RBSDV) (T. Omura, National Agriculture Research Centre, Ibaraki, Japan). The size of each dsRNA segment from infected tobacco was estimated with PstI-digested lambda dsDNA fragments; dsRNA segment sizes of other known plant reoviruses were used as standards (3).

SDS-PAGE. Ten percent polyacrylamide gels (14) were used to compare dsRNA from class I-infected tobacco plants with dsRNA from MRDV, GDV, rice ragged stunt reovirus (RRSV), RBSDV, and WTV. Gels were run at $30 \mathrm{~mA}$ for 30 to $34 \mathrm{~h}$ using Laemmli's (14) buffer system and stained with $6 \mathrm{mM}$ silver nitrate for $30 \mathrm{~min}$. The sizes (base pairs) and total molecular masses (daltons) of dsRNA

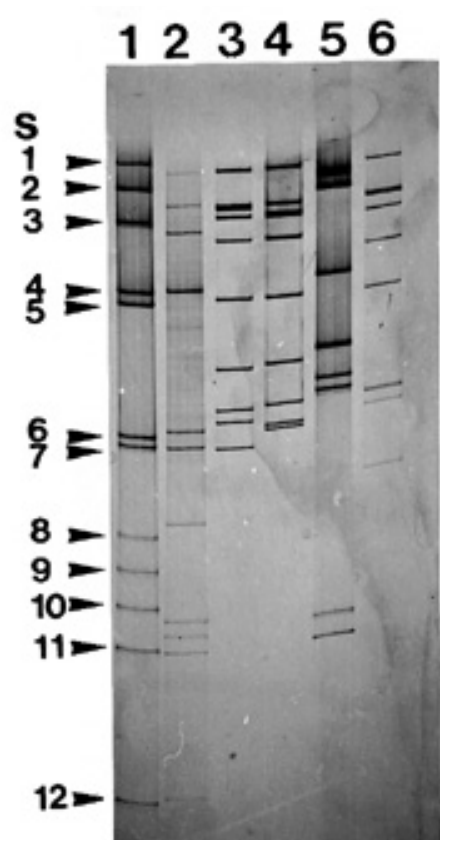

Fig. 3. Sodium dodecyl sulfate-polyacrylamide gel electrophoresis gel (10\%) used to compare dsRNAs isolated from class I leaf curl-infected tobacco (lane 1) with dsRNAs from other reoviruses: lane 2, wound tumor virus; lane 3 , maize rough dwarf fijivirus; lane 4 , rice black-streaked dwarf fijivirus; lane 5, rice ragged stunt reovirus; and lane 6 , garlic dwarf reovirus. dsRNA segments (lane 1, arrows, S1 through S12; sizes are provided in Table 1) from tobacco have unique banding patterns compared with other reoviruses (lanes 2 through 6). 
segments were estimated using the sizes of dsRNAs of other plant-infecting reoviruses as standards.

RNA hybridizations. The four largest tobacco dsRNA segments (S1 to S4) were extracted individually from low melting temperature agarose gels and labeled using the enhanced chemiluminescence labeling and detection system as outlined in the Amersham instruction booklet. Dot blots were probed with four labeled RNAs. Dot blots were prepared by spotting $1 \mu \mathrm{l}(50 \mathrm{ng})$ of heat-denatured dsRNA on Hybond N (Amersham) membranes. dsRNA was fixed on membanes by exposing to UV light for $5 \mathrm{~min}$. S1 to S4 dsRNAs were spotted separately, whereas S5 to S12 dsRNAs were pooled as a single sample and spotted on membranes. Total RNA extractions from class I-infected and healthy tobacco were used as positive and negative controls, respectively.

DNA/RNA hybridizations. Investigation of possible nucleotide sequence homology between the genomes of WTV and the virus isolated from tobacco was undertaken by slot-blot hybridization analysis. Cloned DNAs from WTV segments S4 and S6 to S9 $(1,33)$ were used as probes (provided by N. Suzuki, University of Maryland Biotechnology Institute, College Park). Viral inserts were excised from pGEM plasmid vectors and electrophoresed on $1 \%$ agarose gels, and viral bands were extracted with a Biotech Sephaglas BandPrep kit (Pharmacia LKB Biotechnologies, Piscataway, NJ). DNA probes were digoxigenin (DIG)-labeled, and hybridization and detection were performed with a DIG DNA-labeling and -detection kit (Boehringer). Twelve dsRNAs from WTV and infected tobacco were denatured before they were applied to Hybond $\mathrm{N}$ membranes. RDV and MRDV dsRNAs also were used for comparisons, and positive hybridization controls of denatured WTV S4 and S6 to S9 DNA also were included. Several hybridization temperatures, buffers, and washing solution stringencies were tested. The final hybridization buffer used was the standard buffer from the Boehringer DIG kit. Final prehybridizations were performed at $55^{\circ} \mathrm{C}$ for $6 \mathrm{~h}$, and hybridizations were performed overnight at $55^{\circ} \mathrm{C}$. Slot blots were washed in $2 \times \mathrm{SSC}(1 \times \mathrm{SSC}$ is $0.15 \mathrm{M}$ sodium chloride plus $0.015 \mathrm{M}$ sodium citrate, $\mathrm{pH} 7.0$ ) and $0.1 \% \mathrm{SDS}$ at $55^{\circ} \mathrm{C}$ for $30 \mathrm{~min}$, followed by two washes in $0.5 \times \mathrm{SSC}$ and $0.1 \% \mathrm{SDS}$ at room temperature.

Enzyme-linked immunosorbent assay. Antiserum to MRDV was used in indirect plate enzyme-linked immunosorbent assay (ELISA) (Clark and Adams [4], modified according to the Agdia [Elkhart, IN] instruction manual) to test for possible serological cross-reactivity with the partially purified tobacco virus preparation (described above). Sap extracts from healthy tobacco material were used as negative controls, while partially purified virions of MRDV (unknown concentration) were used as positive controls. Because the concentrations of the tobacco virus and MRDV antigens were unknown, various antigen dilutions were used to optimize ELISA tests. Antigens were used at a final dilution of 1:1,000. MRDV primary antibody (titer 1:256) was optimized at a dilution of 1:1,000. Goat anti-rabbit alkaline phosphatase (Sigma Chemical Co., St. Louis) was used as the secondary antibody at a dilution of 1:10,000. Confidence intervals (CI: $95 \%$ ) were calculated using the mean for healthy tobacco values \pm 2 times the standard deviation. Any significant differences in absorbance values for the samples tested was determined using the $95 \%$ CI of values for healthy tobacco. Values greater than the $95 \%$ CI implied cross-reactivity to the primary antibody tested and were recorded as positive. Any value that was within or below the $95 \%$ CI was recorded as negative.

Immunoslot blots. Tobacco virions purified by sucrose density gradients $(\approx 1 \mathrm{mgl50} \mathrm{g}$ of leaf tissue) were tested for cross-reactivity with antiserum to WTV (ATCC PVAS 235 [American Type Culture Collection, Manassas, VA]) in slot blots, using the amplified alkaline phosphatase goat anti-rabbit immunoblot assay (Bio-Rad Laboratories, Hercules, CA). WTV-infected and healthy clover roots (provided by B. Hillman, Rutgers University, New Brunswick, NJ) were used as positive and negative controls, respectively. Root tissue was ground in the same buffer used for virion extractions, spun briefly at 10,000 rpm to remove heavy debris, and a few grains of $\mathrm{Na}$ azide were added to prevent microbiological deterioration. Healthy tobacco leaf sap extracts also were included as negative controls. Healthy tobacco plant and clover root extracts and tobacco virions were tested at several dilutions, ranging from undiluted to 1:2,000, and a final dilution of 1:100 was selected for best results. The WTV antibody (titer 1:640 to 1:1,280) was used at a dilution of 1:1,000.

\section{RESULTS}

dsRNA species. Twelve dsRNA segments were isolated from class I-infected tobacco plants and designated as segments S1 to S12, from largest to smallest band (Fig. 2A and B; Fig. 3). Segments S4 and S5 appeared as a single band (Fig. 2A) but separated after prolonged electrophoresis (Figs. 2B and 3). The approximate sizes (base pairs) and relative molecular masses (daltons) of each dsRNA segment are shown in Table 1. The relative mobilities of the dsRNAs varied slightly with electrophoretic systems, and the total molecular masses of the dsRNAs were calculated as 17.86 and $18.40 \times 10^{6} \mathrm{Da}$ for SDS polyacrylamide and agarose gels, respectively. The dsRNAs did not bind to the oligo (dT)+ paper in the trapping experiment, indicating the dsRNAs were not polyadenylated (data not shown). Positive-control mRNAs bound successfully to the oligo (dT)+ paper.

Comparison of dsRNA segments isolated from class I-infected tobacco plants with dsRNA of other plant reoviruses. Comparisons of dsRNAs from class I-infected tobacco plants with dsRNA of WTV, RDV, MRDV, RBSDV, RRSV, and GDV are depicted in Figures 2B and 3. Agarose gels (Fig. 2B) were run without WTV and RRSV, and SDS polyacrylamide gels (Fig. 3) were run without RDV. The pattern observed for the 12 dsRNAs isolated from class Iinfected tobacco plants on $1 \%$ agarose gel differed when compared with patterns observed for fijiviruses MRDV and RBSDV and RRSV (an oryzavirus), but the dsRNAs did show certain similarities to dsRNA of RDV, a rice phytoreovirus with 12 dsRNA segments.

The first eight segments ( $\mathrm{S} 1$ to S8) of dsRNA isolated from infected tobacco were similar in size to the first eight segments of RDV dsRNA in agarose gels, whereas the remaining four segments (S9 to S12) differed between the two viruses (Fig. 2B). To obtain improved separation of the 12 dsRNA segments isolated from infected tobacco plants, a 30-cm SDS polyacrylamide gel was run (Fig. 3). All doublets separated well (Fig.3, lane 1), and the banding pattern was compared with those of WTV, RDV, MRDV, RBSDV, RRSV, and GDV. The banding pattern of dsRNA isolated from class I-infected tobacco differed significantly from MRDV, RBSDV, RRSV, and GDV but showed some similarities to WTV. Size distribution of segments S4, S7, S11, and S12 of class I-infected tobacco (Fig. 3, lane 1) and WTV (Fig. 3, lane 2) were similar, whereas segments S1 through S3, S5, S6, and S8 through S10 were dif-

TABLE 1. Estimated numbers of base pairs and relative molecular masses of dsRNAs isolated from tobacco exhibiting class I leaf curl symptoms

\begin{tabular}{|c|c|c|c|c|}
\hline \multirow{2}{*}{$\begin{array}{l}\text { dsRNA } \\
\text { segments }\end{array}$} & \multicolumn{2}{|c|}{$\begin{array}{l}\text { Approximate no. } \\
\text { of base pairs }\end{array}$} & \multicolumn{2}{|c|}{$\begin{array}{l}\text { Relative molecular masses } \\
\qquad\left(\times 10^{6} \mathrm{Da}\right)\end{array}$} \\
\hline & Agarose gel & SDS-PAGE $^{\mathrm{a}}$ & Agarose gel & SDS-PAGE \\
\hline S1 & 4,786 & 4,570 & 3.25 & 3.10 \\
\hline $\mathrm{S} 2$ & 3,845 & 3,913 & 2.61 & 2.66 \\
\hline S3 & 3,467 & 3,342 & 2.36 & 2.27 \\
\hline S4 & 2,735 & 2,600 & 1.86 & 1.77 \\
\hline S5 & 2,691 & 2,470 & 1.83 & 1.68 \\
\hline S6 & 1,778 & 1,718 & 1.21 & 1.17 \\
\hline S7 & 1,745 & 1,704 & 1.19 & 1.16 \\
\hline S8 & 1,468 & 1,442 & 1.00 & 0.98 \\
\hline S9 & 1,291 & 1,334 & 0.88 & 0.90 \\
\hline $\mathrm{S} 10$ & 1,230 & 1,225 & 0.84 & 0.83 \\
\hline S11 & 1,169 & 1,138 & 0.79 & 0.77 \\
\hline $\mathrm{S} 12$ & 860 & 844 & 0.58 & 0.57 \\
\hline Total size & 27,065 & 26,300 & 18.40 & 17.86 \\
\hline
\end{tabular}

a Sodium dodecyl sulfate-polyacrylamide gel electrophoresis. 
ferent. S1 through S3 of tobacco appeared to be larger than the corresponding WTV segments. Minor bands (electropherotypes) were observed with segments S3, S7, S8, and S12 (Fig. 3, lane 1), indicating the possibility of heterogeneity in the mobility of individual segments (Fig. 3).

Nucleic acid hybridizations. Hybridizations of each of the endlabeled S1 to S4 dsRNA probes to the corresponding S1 to S4 segments (positive control) occurred, but there were no cross-hybridizations between the four dsRNA species, nor was there any cross-hybridization of the S5 to S12 dsRNA segments with the S1 to S4 probes (data not shown). No hybridization occurred between DIG-labeled WTV S4 and S6 to S9 fragments or any dsRNAs from tobacco (data not shown). Positive signals were obtained with WTV total dsRNA and homologous S4 and S6 to S9 DNA probes. Positive hybridizations also occurred with the respective $\mathrm{S} 4$ and S6 to S9 cloned DNA controls. No hybridizations took place with RDV or MRDV (negative controls) and WTV probes.

Virus extractions. Virions extracted from all infected tobacco material over 4 years were identical in shape and size. Electron microscopy of virus particles and negative staining revealed icosahedral particles that had an outer core $\approx 60$ to $65 \mathrm{~nm}$ in diameter and appeared to have an inner smooth core 40 to $45 \mathrm{~nm}$ in diameter but lacking spikes (Fig. 4A and B). The virions appeared more angular than spherical in sodium phosphotungstate-negative stain at neutral $\mathrm{pH}$, which does not occur with fijiviruses.

Virus yields from all sources of tobacco were similar for extractions from frozen material and were low and roughly estimated to be 1 to $2 \mathrm{mg} \backslash 50 \mathrm{~g}$ of leaf material. However, the yield for extraction from fresh material appeared to be approximately fivefold higher compared with frozen material.

Twelve segments of dsRNA that corresponded with those extracted from infected tobacco plants were successfully isolated from purified virions (Fig. 2C). Segments S4 and S5 and S6 and S7 appeared as single bands (Fig. 2C).
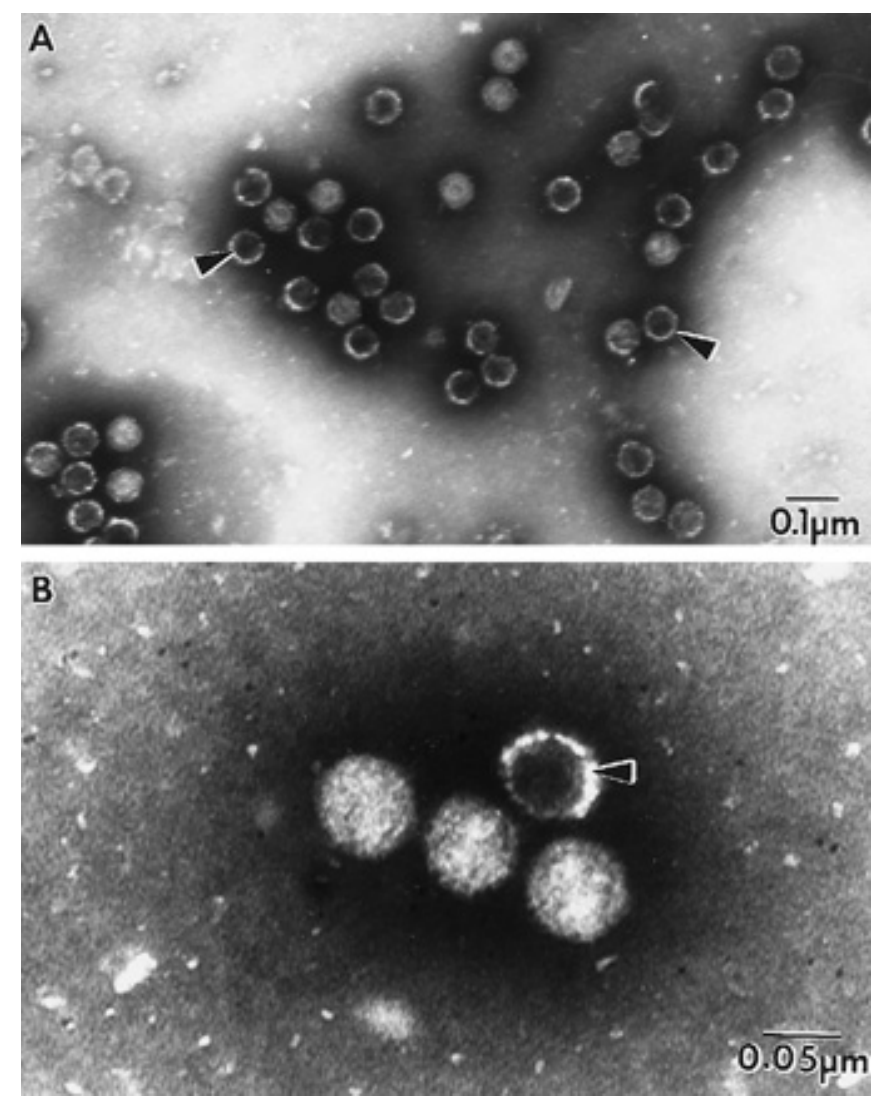

Fig. 4A and B, Electron micrographs of icosahedral particles (arrows in A) (inner core diameter 40-45 nm; outer diameter $60-65 \mathrm{~nm}$; arrow in $\mathbf{B}$ ) isolated from class I leaf curl-infected tobacco. A, Bar $=100 \mathrm{~nm} ; \mathbf{B}$, bar $=50 \mathrm{~nm}$.
ELISA. Antiserum to MRDV, a member of the genus Fijivirus, was used in ELISA. A 95\% CI for each ELISA value was determined, and values were recorded as either positive or negative. The values obtained with MRDV antiserum for class I-infected tobacco material were not significantly different from negative healthy controls (data not shown). Positive binding of MRDV antibodies to the MRDV positive control was observed.

Immunoslot blots. WTV extracts from infected clover roots (positive control) and sucrose gradient density-purified tobacco virions showed strong serological cross-reactivity with antiserum to WTV (Fig. 5A and B, slots 1 through 3). No reaction was detected with healthy clover extracts (Fig. 5A, slots 4 through 6) and healthy tobacco extracts (Fig. 5B, slots 4 through 6). A positive reaction was observed with the primary antibody control (Fig. 5A and B, slots 7).

\section{DISCUSSION}

Virus particles resembling phytoreoviruses were consistently isolated from leaf curl-infected tobacco from the eastern and western tobacco-growing regions of South Africa. Initial extractions from tobacco during the first few years of our research were aimed at isolating geminiviruses, because the literature reported that leaf curl was caused by whitefly-transmitted geminiviruses $(16,23)$. Only after enough evidence was available to reveal the absence of a geminivirus in class I-infected tobacco, were reovirus extractions attempted. Consequently, the majority of subsequent reovirus extractions were performed on stored frozen $\left(-80^{\circ} \mathrm{C}\right)$ leaf material, which was the only material available until recently, when an extraction was performed on fresh leaves. Virus yields generally were low from leaf tissue but improved when fresh material, $\approx 20 \mu \mathrm{g}$ (frozen) to $100 \mu \mathrm{g}$ (fresh) per $\mathrm{g}$ fresh weight, was used. Lack of available plant tissue and low virus yields did not allow comprehensive protein characterization, although some preliminary PAGE and Western blots were achieved and further work is being done.

The sizes of dsRNAs isolated from class I-infected tobacco plants and virions purified from infected plants were estimated to be similar in range but larger in total size (17.86 to $18.40 \mathrm{kDa}$ ) (Table 1) compared with reported sizes for WTV and other phytoreovirus dsRNAs (15 to $17 \mathrm{kDa}$ ) (17). Depending on the electrophoretic system used, the total molecular mass of the WTV genome has been estimated at 15.06 (27), 16.02 to 16.67 (28), and 16.04 to $16.67 \mathrm{kDa}(29)$. However, to our knowledge, segments S1 through S3 have not been sequenced for WTV, and based on the available sequence sizes of the smaller dsRNAs, it is probable that the total size estimations in the literature are inaccurate and should be larger. The phytoreovirus dsRNA sizes reported in the literature are collectively smaller than the total molecular masses of the 10 dsRNA segments of fijiviruses (18 to $20 \mathrm{kDa}$ ) (19). Furthermore, the size distribution of the dsRNAs, the lack of $3^{\prime}$ poly(A) tracts, and the angular shape of the virus particles from tobacco also were inconsistent with the presence of fiji-, oryza-, or GDV-like reoviruses

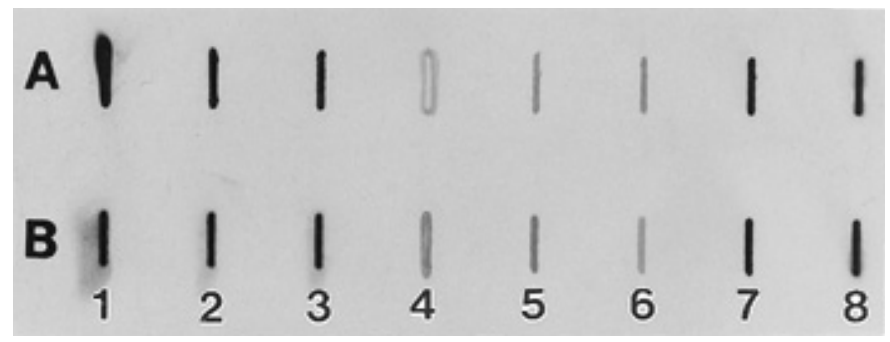

Fig. 5. Immunoslot blot assay of tobacco virions cross-reacting with antiserum to wound tumor virus (WTV) $(1: 1,000)$. A, Slots 1 through 3: WTV; slots 4 through 6: healthy clover. B, Slots 1 through 3: tobacco virus; slots 4 through 6: healthy tobacco; A and B, slot 7: primary antibody $(1: 1,000)$ control; slot 8: biotinylated polyacrylamide gel electrophoresis marker control. Slot 1: undiluted sample; slot 2: 1:10 sample dilution; slot 3: 1:20 sample dilution. 
$(11,22)$. Variations in electrophoretic mobilities of dsRNA segments from infected tobacco were noted. Electropherotypes have been reported for several plant-infecting reoviruses, for example MRDV (18).

A previous study demonstrated that segments S1 through S8 of WTV and RDV exhibited a very similar pattern after coelectrophoresis through agarose gels (29), which was consistent with results obtained in our study, in which we compared the dsRNA segments of RDV and WTV $(27,28)$ to the dsRNA segments isolated from class I-infected tobacco plant material. The banding pattern of dsRNAs isolated from infected tobacco was unique but most similar to the banding pattern of the phytoreovirus WTV $(27,29)$. The first eight segments of RDV, WTV, and dsRNA isolated from class I-infected tobacco exhibited similar electrophoretic mobilities through agarose and SDS polyacrylamide gels, respectively (Figs. 2B and 3). The differences in dsRNA pattern and total genome size between WTV and the tobacco virion suggest the virus isolated from class I-infected tobacco plants may be a new phytoreovirus; this theory is supported further by the lack of crosshybridization between S4 and S6 to S9 of WTV and dsRNAs from infected tobacco. Similarities between particles isolated from class Iinfected tobacco and those from intact wild-type WTV (29) were observed, and a serological relationship was established between WTV and the tobacco virus proteins by immunoslot-blot ELISA. To date, no serological relationships have been demonstrated between the only fully characterized dicot phytoreovirus and other phytoreoviruses. However, a serological relationship has been established between RDV and rice gall dwarf reovirus, which are monocot phytoreoviruses $(8,11,22)$. Serological results do not support the presence of a fijivirus in class I-infected tobacco plants, because no antigen binding was observed with MRDV antiserum.

In summary, particle morphology, size, and pattern of dsRNAs and serological data demonstrated that dsRNAs isolated from class Iinfected tobacco represent the genome of a member of the genus Phytoreovirus. In addition, symptoms of leaf enations, vein swellings, and root tumors in tobacco showed a distinct similarity to symptoms reported for the only dicot-infecting phytoreovirus, WTV $(2,11)$. The tobacco virus appears to be serologically related to WTV, but lack of significant sequence homology and differences in dsRNAs between WTV and the tobacco virus suggest a distinct phytoreovirus. Cloning and molecular characterizations are required to establish the identity of the tobacco virus and its relationship to other phytoreoviruses. The virus isolated from class I-infected tobacco in South Africa is the first report of a phytoreovirus in tobacco, the first record in Africa, and the second example of a field-isolated phytoreovirus; the first field isolation was performed in 1991 (10). We propose the name tobacco leaf enation virus (TLEV) for our virus isolate. The etiology of the disease in tobacco needs to elucidated, and the vector must be identified in further studies.

\section{ACKNOWLEDGMENTS}

We thank T. Omura for supplying GDV and RDV dsRNAs; B. Hillman for WTV antigen and dsRNAs; and N. Suzuki for WTV clones. We also thank the University of the Witwatersrand for partial funding.

\section{LITERATURE CITED}

1. Anzola, J. V., Dall, D. J., Xu, Z., and Nuss, D. L. 1989. Complete nucleotide sequence of wound tumor virus genomic segments encoding nonstructural polypeptides. Virology 171:222-228.

2. Black, L. M. 1945. A virus tumor disease of plants. Am. J. Bot. 32:408-415.

3. Boccardo, G., Milne, R. G., Disthaporn, S., Chettanachit, D., and Putta, M. 1985. Morphology and nucleic acid of rice gall dwarf virus. Intervirology 23:167-171.

4. Clark, M., and Adams, A. N. 1977. Characteristics of the microplate method of enzyme-linked immunosorbent assay for the detection of plant viruses. J. Gen. Virol. 34:475-483.

5. Dall, D. J., Anzola, J. V., Xu, Z., and Nuss, D. L. 1989. Complete nucle- otide sequence of wound tumor virus genomic segments S11. Nucleic Acids Res. 17:3599.

6. Duyver, L. 1990. An investigation of the causal agent(s) and transmission of tobacco leaf curl disease. Honors thesis. University of Witwatersrand, Johannesburg, South Africa.

7. Forster, G. 1990. The isolation, characterization and transmission of tobacco leaf curl disease, M.Sc. thesis. University of Witwatersrand, Johannesburg, South Africa.

8. Francki, R. I. B., and Boccardo, G. 1983. The plant Reoviridae. Pages 505-563 in: The Reoviridae. W. K. Joklik., ed. Plenum Press, NY.

9. Hill, S. A. 1984. Electron microscopy. Pages 130-163 in: Methods in Plant Virology. Blackwell Scientific Publications, Oxford.

10. Hillman, B. I., Anzola, J. V., Halpern, B. T., Cavileer, T. D., and Nuss, D. L. 1991. First field isolation of wound tumor virus from a plant host: Minimal sequence divergence from the type strain isolated from an insect vector. Virology 185:896-900.

11. Holmes, I. H., Boccardo, G., Estes, G., Furuichi, M. K., Hoshino, Y., Joklik, W. K., McCrae, M., Mertens, P. P. C., Milne, R. G., Samal, K. S. K., Shikata, E., Winton, J. R., Uyeda, I., and Nuss, D. L. 1995. Reoviridae. Virus Taxonomy: Classification and Nomenclature of Viruses. Pages 208-239. 6th Rep. Int. Commit. Taxon. Viruses. Archives of Virology, Supplement 10. SpringerVerlag, Vienna.

12. Kimura, I. 1976. Improved purification of rice dwarf virus by the use of polyethylene glycol. Phytopathology 66:1470-1474.

13. Koganezawa, H., Hibino, H., Motoyoshi, F., Kato, H., Noda, H., Ishikawa, K., and Omura, T. 1990. Nucleotide sequence of segment S9 of the genome of rice gall dwarf virus. J. Gen. Virol. 71:1861-1863.

14. Laemmli, U. K. 1970. Cleavage of structural proteins during assembly of the head of bacteriophage T4. Nature (Lond.) 227:680-685.

15. Lot, H., Delecolle, B., Boccardo, G., Marzachi, C., and Milne, R. G. 1994. Partial characterization of reovirus-like particles associated with garlic dwarf disease. Plant. Pathol. 43:537-546.

16. Lucas, G. B. 1975. Diseases of Tobacco. 3rd ed. H. E. Parker and Sons, North Carolina.

17. Maramorosch, K. 1977. Plant Reovirus Group. Pages 377-381 in: The Atlas of Insect and Plant Viruses. Academic Press, London.

18. Marzachi, C., Boccardo, G., and Caciagli, P. Heterogeneity of maize rough dwarf fijivirus genomic segments isolated from 1997 field infection. Z. Pflanzenkrank. Pflanzenschutz. In Press.

19. Marzachi, C., Boccardo, G., Milne, R., Isogai, M., and Uyeda, I. 1995. Genome structure and variability of fijiviruses. Semin. Virol. 6:103-108.

20. Morris, T. J., and Dodds, J. A. 1979. Isolation and analysis of doublestranded RNA from virus infected plant and fungal tissue. Phytopathology 69:854-858.

21. Noda, H., and Nakashima, N. 1995. Non-pathogenic reoviruses of leafhoppers and planthoppers. Semin. Virol. 6:109-116.

22. Omura, T. 1995. Genomes and primary protein structures of phytoreoviruses. Semin. Virol. 6:97-102.

23. Osaki, T., and Inouye, T. 1978. Resemblance in morphology and intranuclear appearance of viruses isolated from yellow dwarf diseased tomato and leaf curl diseased tobacco. Ann. Phytopathol. Soc. Jpn. 44:167-178.

24. Osaki, T., and Inouye, T. 1981. Tobacco leaf curl virus. CMI/AAB Descriptions of Plant Viruses 232. Association of Applied Biologists, Wellesbourne, England.

25. Paximadis, M., Dusterwald, G., Duyver, L., and Rey, M. E. C. 1997. Preliminary investigation of a disease causing leaf curl of tobacco in South Africa. Plant Pathol. 46:282-290.

26. Paximadis, M., and Rey, M. E. C. 1997. Aetiology of tobacco leaf curl in southern Africa. Ann. Appl. Biol. 131:449-457.

27. Reddy, D. V. R., and Black, L. M. 1973. Electrophoretic separation of all components of the double-stranded RNA of wound tumor virus. Virology 54:557-562.

28. Reddy, D. V. R., and Black, L. M. 1977. Isolation and replication of mutant populations of wound tumor virions lacking certain genomic segments. Virology 80:336-346.

29. Reddy, D. V. R., Kimura, I., and Black, L. M. 1974. Co-electrophoresis of dsRNA from wound tumor and rice dwarf viruses. Virology 60:293296.

30. Sambrook, J., Fritsch, E. F., and Maniatis, T. 1989. Molecular Cloning: A Laboratory Manual. Cold Spring Harbor Laboratory Press, Cold Spring Harbor, NY.

31. Thatcher, J. 1976. Whitefly transmission and etiology of tobacco leaf curl disease. M.S. thesis. University of Natal, Pietermaritzburg, South Africa.

32. Valand, G. B., and Muniyappa, V. 1992. Epidemiology of tobacco leaf curl virus in India. Ann. Appl. Biol. 120:257-267.

33. Xu, Z., Anzola, J. V., and Nuss, D. L. 1989. Assignment of wound tumor virus nonstructural polypeptides to cognate dsRNA genome segments by in vitro expression of tailored full-length cDNA clones. Virology 168:73-78. 